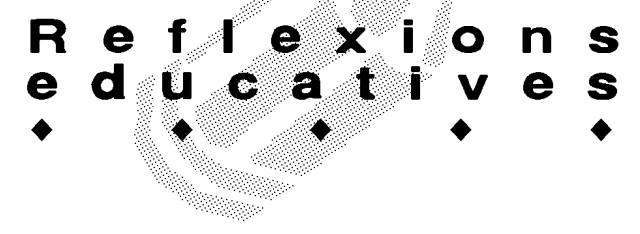

\title{
EL PSICOPEDAGOG DAVANT LA NEOVIOLĖNCIA A L'ESO
}

\author{
Jordi Solé Blanch i Verònica Vallverdú Llauradó. Llicenciats en Pedagogia per la URV
}

\section{Introducció}

Els mitjans de comunicació estan publicant últimament que en els nuclis urbans més importants de la província de Tarragona, i més concretament, en el triangle format per les ciutats de Tarragona, Reus i Valls, s'estan donant casos de bregues entre nois i noies de 12 a 18 anys a les mateixes portes dels nostres centres d'educació secundària. Sigui perquè aquestes baralles estan sent motivades per mòbils xenòfobs 0 racistes, o perquè hi ha la disputa de sempre entre bandes organitzades, el cas és que la violència en els centres no està sent motiu exclusiu de les institucions educatives nord-americanes, franceses o britàniques.

Com ja havíem estudiat el curs 96/97 ["Universitarios de Tarragona actúan para evitar conductas antisociales", EL PERIODICO DE CATALUNYA, 11/5/96. "La Generalitat dice que tomará medidas para frenar la intensificación de la violencia escolar", article publicat per LA VANGUARDIA el 5/12/96, on es mostren les dades $i$ conclusions del nostre estudi], amb l'anterior sistema educatiu moltes d'aquestes manifestacions violentes eren protagonitzades per joves entre 14 i 16 anys, que es quedaven al carrer després de segregacions prematures a què obligava la doble opcionalitat dels estudis post-obligatoris. Actualment, aquests alumnes estan escolaritzats i pertoca al sistema educatiu la corresponsabilització de les tasques preventives. Aquesta opció de base amb què es democratitza l'educació secundària "es tradueix en un model d'escola comprensiva" (Generalitat de Catalunya, 1993), per integrar la diversitat dels alumnes, "tant pel que fa als processos i ritmes d'aprenentatge com a les actituds relatives a l'escola" (Ibidem), així com a les aptituds, interessos i cultures pròpies. I per fer-ho possible, la LOGSE dota als centres d'un nou tipus de docent, el psicopedagog, que ha d'esdevenir el motor de l'atenció a la diversitat.

En aquest article analitzem, precisament, una de les seves funcions a l'hora d'atendre i preveure els comportaments agressius que molts joves manifesten amb els seus impulsos, de vegades, incontrolats; principalment dels nois, però, com ja hem dit en estudis precedents, amb la incorporació progressiva de les noies.

\section{L'estat de la qüestió}

¿Què passa amb aquests alumnes que fan de la violència el seu instrument de relació en un centre de Secundària? Aquesta va ser una de les qüestions amb què vàrem interrogar, precisament, la psicopedagoga de I'IES de Riudoms, Maria Teresa Molas.

"El primer que cal veure és -afirma la professora Molas- que si hi ha violència és perquè existeix socialment, i no podem tancar els ulls davant d'ella". Aquesta postura és necessària per entendre que els comportaments agressius tenen una explicació social i que, per tant, les portes de la reeducació queden obertes. Són les condicions socials $i$ econòmiques les que generen aquests comportaments, i no tant les característiques personals dels qui les realitzen.

Algunes tesis de la ciència criminològica, prou coneixedora del fenomen de la delinqüència juvenil, defensen l'explicació multifactorial a l'hora de buscar l'etiologia de les respostes violentes d'aquests grups de risc. Fuentes i Beltran (1996), en aquest sentit, apunten que "cuando juzguemos ciertos hechos violentos, basados en acusaciones verídicas, tenemos que entender que sus actores, además de ser jóvenes, son hijos de unos padres, personas de nuestra propia cultura, víctimas de unas condiciones sentimentales, educativas y laborales que reprimen y anulan parte de su potencial expresivo", (pàg. 83). La incomunicació familiar o el trencament d'aquesta estructura envers la creació del món subcultural del grup d'amics o de la banda, la influència nociva dels mitjans de comunicació o "el papel iniciático que los modelos fílmicos ejercen con perversión sobre una infancia que observa inconscientemente los programas reiterativos de la televisión, o hace del matar un juego interactivo", (Ibidem), la glorificació de la competitivitat-com ens recorda Rojas Marcos (1995)-, etc. van creant les condicions necessàries per a les respostes agressives "que s'aprenen" -com ens diu la professora Molas-, i "comienzan a dar sus frutos malignos en la adolescencia", (Rojas Marcos, 1995).

\section{Els mitjans i la prevenció}

Però si la Sociologia ens ofereix l'oportunitat d'ex- 


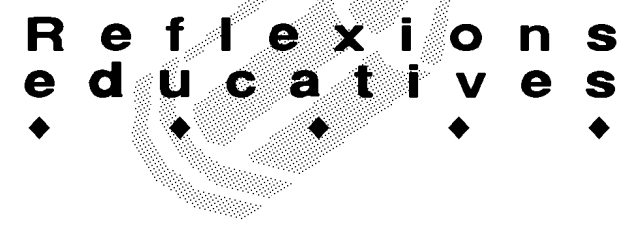

plicar aquests fenòmens, la Pedagogia hi ha de trobar les seves respostes, i l'Administració els mitjans per a una educació pertinent.

"La Direcció General d'Ensenyament -apunta la professora Molas- ha apostat fort per les UAC's (Unitats d'Adaptació del Currículum)". "Es busca una via alternativa i complementària per a l'assoliment dels objectius de l'etapa" (DOGC, 669/pàg. 1229) que, unida a les altres mesures d'atenció a la diversitat de què disposen els centres, "alleujarà el fracàs escolar" -segons la professora Molas-. La UAC es converteix així en un instrument més d'integració adreçada a alumnes amb necessitats educatives greus, com podrien ser les desviacions de conducta que aquí estem exposant. Amb aquesta nova disposició, l'Administració amplia el marc de les accions integradores sense les quals l'anterior sistema educatiu perdia casos de nois i noies perfectament recuperables. Però si ella ha sabut col-locar-se en una situació exculpatòria, (ja que no serà que per la normativa pedagògica els deterministes socials podran atribuir-li el foment de segregacions desigualitàries), ara s'exigeix un canvi de mentalitat del professorat, que ha de substituir "l'expulsió" com a mesura de càstig dels indisciplinats per "l'acolliment individualitzat".

"Les mesures o pautes d'intervenció que cal prendre envers els alumnes conflictius -segons la professora Molas- dependrà del que sigui positiu per a aquests". El psicodiagnòstic demostra sempre que no existeixen les solucions universals, però el rerefons integrador amara tot el discurs pedagògic de la Reforma, tot i sabent que

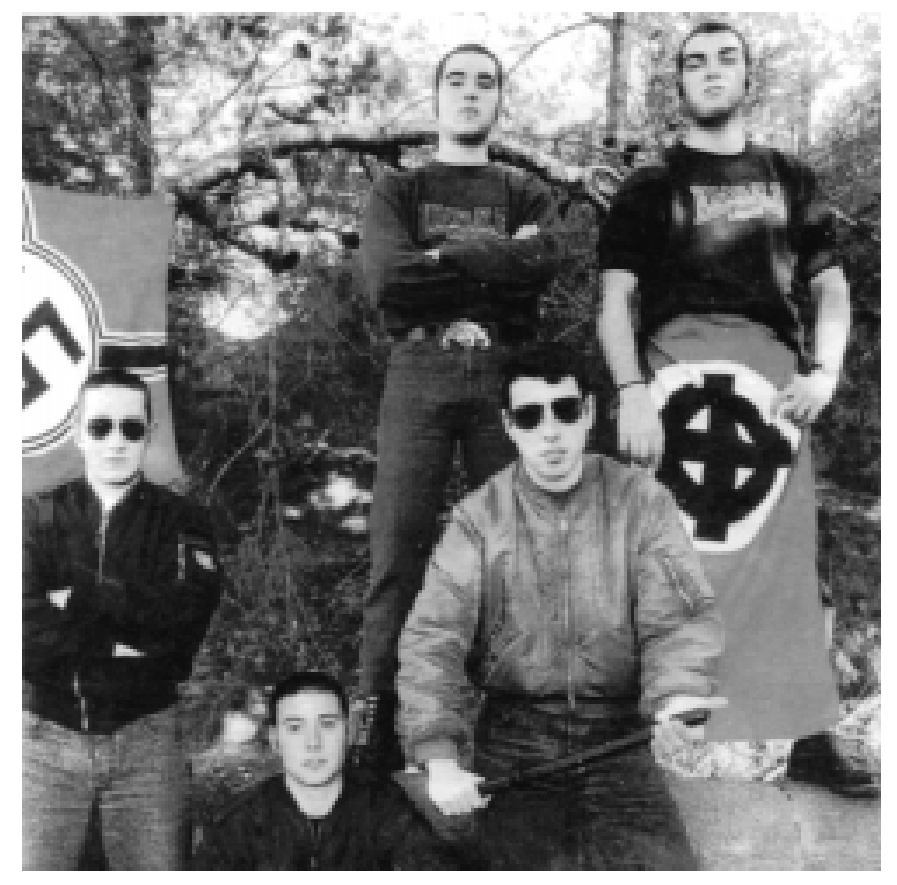

el mecanisme reactiu de molts d'aquests nois i noies 0 bé es manifesta amb un atac frontal a la cultura i al quadre d'institucions socials, o bé es canalitza per la via del desenteniment, sense necessitat de provocar mecanismes escandalosos en el marc dels formalismes socials. Trobar, per tant, projectes motivadors és imperatiu si es vol promoure el canvi d'hàbits perillosos. En aquest sentit, la professora Molas apunta que "els educadors de barri ens han ensenyat molt al respecte, proposant la necessitat de crear vincles afectius amb aquest joves". Guanyar-se'ls per la via de l'afecte, després veurem com podrem ajudar-los, tenint sempre presents poques garanties d'èxit, mentre les nostres possibilitats d'intervenció siguin mínimes.

Entre aquests mínims, la tutoria individualitzada apareix com un dels millors moments que tenen els tutors i les tutores, (sobretot si són joves i amb actituds engrescadores), per realitzar aquests apropaments afectius. Però la relació amb aquests/es alumnes, com amb tots/es, ha de ser un compromís de tot el centre. "El psicopedagog es veu obligat a conscienciar el treball intersectorial, és a dir, des del conserge fins a l'equip directiu" -segons la professora Molas-, en el qual s'estableixi una acció comuna per la via de l'autoestima. No es tracta, per tant, de posar en evidència els comportaments rebutjables ni optar per les vies estrictament repressives, sinó de fer un esforç empàtic per tal de comprendre'ls i reforçar, després, les conductes positives. I és que el tractament de la violència en els nostres centres educatius exigeix entendre que no només cal desenvolupar un currículum actitudinal des de les primeres etapes d'escolarització, sinó que també cal una implicació professional dels/les professors/es fora de l'exclusiu i reduït món de les aules.

\section{Bibliografia consultada}

ALGORI, I. i FERNÁNDEZ, A. Tribus Urbanas. «Tiempo» (14-3-1994) Pàg. 12.

ALUJA, A. Personalidad desinhibida, agresividad y conducta antisocial. Edita PPU. Barcelona. 1991.

FUENTES, E. i BELTRAN, J.M. (1996): Violencia y rebelión juveniles. Sobre la educación y la prevención. «Universitas Tarraconensis», Revista del Departament de Pedagogia de la URV. (1996) 79-96.

GENERALITAT DE CATALUNYA. Currículum ESO. Departament d'Ensenyament, Servei de Difusió i Publicacions. 1993. Pàg. 12.

ORTET, G. Actituds de professionals relacionats amb la delinqüència envers les causes, la prevenció i el tractament. Editorial Universitat Autònoma de Barcelona. 1991.

ROJAS MARCOS, J. L. La semilla de la violencia. EpasaCalpe. Madrid. 1995.

URRA, J. Adolescentes en conflicto. Editorial Pirámide. Madrid. 1995. 